\section{Combined intravenous pulse methylprednisolone and oral cyclosporine $A$ in the treatment of corneal graft rejection: 5-year experience}

AL Young ${ }^{1}$, SK Rao ${ }^{1,2}$, LL Cheng ${ }^{1}$, AKK Wong ${ }^{1}$, ATS Leung ${ }^{1}$ and DSC Lam
${ }^{1}$ Department of Ophthalmology \& Visual Sciences The Chinese University of Hong Kong

Prince of Wales Hospital Shatin, NT, Hong Kong

${ }^{2}$ Sankara Nethralaya

Chennai

Tamil Nadu, India

Correspondence:

Prof DSC Lam

Chairman

Department of

Ophthalmology

\& Visual Sciences

The Chinese University of

Hong Kong

University Eye Centre

Hong Kong Eye Hospital

147K, Argyle Street

Hong Kong

Tel: (852) 27623157

Fax: (852) 21941369

E-mail: dennislam@

cuhk.edu.hk

\begin{abstract}
Purpose To report the mid-term results of a treatment strategy using topical steroids, intravenous pulse methyl prednisolone and oral cyclosporine A (CSA) for the treatment of acute corneal graft rejection.

Methods Noncomparative, interventional case series. Treatment of corneal graft rejection included $1 \%$ prednisolone eye drops, intravenous infusion of $500 \mathrm{mg}$ methyl prednisolone, and oral CSA in two regimens-standard dose was $15 \mathrm{mg} / \mathrm{kg} /$ day for 2 days, $7.5 \mathrm{mg} / \mathrm{kg} /$ day for 2 days, then adjusted to maintain trough blood levels of $100-200 \mu \mathrm{g} / \mathrm{l}$; low dose was $2 \mathrm{mg} / \mathrm{kg} /$ day with no loading dose.

Results Outcome in 34 eyes of 34 patients

(21 M;13 F) aged $60 \pm 17.7$ years (range 9-83 years), who presented after an average duration of $6.6 \pm 6.3$ days (range $0-30$ days) following acute corneal graft rejection, are reported. Twenty-five patients received standard dose CSA while nine patients received the low dose regimen. Mean duration of treatment before reversal of graft rejection was $13.6 \pm 12.1$ days (range 3-54 days). Treatment was successful in reversing the graft rejection in $32 / 34(94 \%)$ eyes. Irreversible graft failure occurred in one eye in each group. During a mean follow-up period of $19.2 \pm 16.7$ months (range 1-55 months), further episodes of graft rejection were seen in $1 / 32(3 \%)$ eyes. Complications due to treatment included: duodenal ulcer in one patient that responded to medical treatment, and transient elevation in serum
\end{abstract}

creatinine levels in three patients, which returned to normal after decrease in dosage or cessation of oral CSA.

Conclusion Our 5-year experience with the use of oral CSA in the treatment of acute corneal graft rejection has shown this treatment approach to be safe and effective in reversing the rejection process. This approach may also protect the graft from subsequent episodes of allograft rejection. A randomised controlled trial to further delineate the role of CSA in reversing acute graft rejection seems warranted.

Eye (2002) 16, 304-308. DOI: $10.1038 /$

sj/eye/6700144

Keywords:

allograft rejection; corneal transplant; corticosteroids; cyclosporine A; methyl prednisolone

\section{Introduction}

The cornea is an immunologically privileged site within the human body and hence, corneal grafting is a successful procedure with a first year survival rate of up to $90 \% .{ }^{1,2}$ However, long-term 10-year survival rate drops to $62 \%,{ }^{2}$ and in 'high risk' eyes can be as low as $35 \%$. $^{3}$ The most common cause of corneal graft failure is allograft rejection, ${ }^{4}$ and endothelial damage accounts for most of the morbidity. Previous studies have indicated that prompt treatment and reversal of endothelial rejection episodes are associated with a better anatomical and functional 
outcome in the corneal graft. ${ }^{5}$ Treatment of corneal graft rejection however, remains empirical although steroids continue to be the mainstay of treatment. Recommendations include the use of topical and/or periocular steroids, either alone, ${ }^{6}$ in combination with oral steroids, ${ }^{7}$ pulse intravenous methyl prednisolone, ${ }^{8}$ or both. ${ }^{9}$ Except for one recent report ${ }^{6}$ which indicated a $92 \%$ success in reversing graft rejection using topical and intravenous steroids, the success rate in other published studies has been less than $80 \% .^{7-9}$ Although cyclosporine A (CSA) has been shown to be effective in preventing corneal graft rejection, especially in high risk eyes, ${ }^{10}$ its usefulness in treating acute corneal graft rejection is less clear. Its role in the treatment of acute cadaveric renal allograft transplantation was first reported in 1983, ${ }^{11}$ and our group has used a combination of topical steroids, intravenous pulse methyl prednisolone, and oral CSA in the treatment of acute corneal graft rejection. We have previously reported the short-term results of this approach using standard dose, ${ }^{12}$ and low dose CSA. ${ }^{13}$ Since then we have treated a larger cohort of patients and report our 5-year experience in this study.

\section{Materials and methods}

The case records of patients with acute corneal graft rejection diagnosed at the Prince of Wales Hospital, Hong Kong, China between April 1995 and March 2000 were analysed. Graft rejection was defined as an eye with a previously clear and thin graft, now showing some or all of the following signs: anterior chamber flare and cells, keratic precipitates on corneal endothelium, thickening of the graft, either diffusely or locally, and epithelial or endothelial rejection lines. Exclusion criteria included a refusal on the part of the patient, or the patient's guardian, to participate in the study, and symptoms of graft rejection longer than 4 weeks before presentation. Reversal of graft rejection was defined as the resolution of corneal oedema. All patients received 1\% prednisolone eye drops at hourly intervals through the night for 3 days, hourly from 8 am to 12 midnight for 4 days, and the dosage was then tapered according to the clinical response. Once the rejection was reversed, topical steroids were then gradually reduced to a long-term maintenance level of topical fluorometholone once daily. Intravenous infusion of $500 \mathrm{mg}$ of methyl prednisolone was administered over one hour.

Although the treatment of corneal graft rejection remains empirical, the reason for choosing this intense regimen of topical steroid was based on our clinical observation that the combination of a lower frequency of topical steroid together with pulse steroid appeared to be less effective than the above regime. Oral CSA was used in two dosages-11 patients treated between April 1995 and December 1996 received the standard dose-after an initial loading dose of $15 \mathrm{mg} / \mathrm{kg} /$ day for 2 days and $7.5 \mathrm{mg} / \mathrm{kg} /$ day for another 2 days, the dose was adjusted to maintain therapeutic trough blood levels of 100-200 $\mu \mathrm{g} / 1$ and was continued for 6 months after the rejection was reversed. Nine patients treated between January 1997 and September 1998 received the low dose regimen $-2 \mathrm{mg} / \mathrm{kg} /$ day of oral CSA was administered, with no loading dose, for 6 months after the rejection was reversed. The optimal duration of CSA therapy is not known. As there are potential systemic side effects associated with CSA, the authors had previously attempted to titrate down the duration of therapy. It was clinically observed that patients responded well to 6 months of systemic CSA and hence this duration was chosen.

As discussed in our earlier report, ${ }^{13}$ the low dose regimen was less effective in reversing graft rejection and also in preventing further such episodes. We thus treated patients presenting to us after October 1998 with the standard dose regimen of CSA. In this combined non-comparative series, due to the late presentation of many cases and the scarcity of grafts in the local community, the patients who presented to us within 4 weeks of the rejection episode were also included, in contrast to 2 weeks for the previous reports. ${ }^{12,13}$

\section{Results}

In the specified study period, 34 patients fulfilled the study criteria (short-term follow-up results of 20 of these patients have already been described in earlier reports). ${ }^{12,13}$ Briefly, we had previously discovered that in 11 patients receiving the combined regimen of intensive topical steroid, intravenous methylprednisolone and oral CSA with loading dose, a reversal rate of $90.9 \%$ was achieved. ${ }^{12}$ Subsequently, nine patients received a low dose regime of the treatment as above except without any loading dose of CSA. However, the low dose regime appeared to be less effective in rejection reversal and was hence terminated. In this current combined series, there were 21 male and 13 female patients, with a mean age of 60 \pm 17.7 years (range 9-83 years). Mean time interval from the most recent graft to the onset of rejection was $25.8 \pm 24.9$ months (range 1-120 months), while the mean delay in presentation to clinic after onset of symptoms was $6.6 \pm 6.3$ days (range $0-30$ days). One patient reported no symptoms at presentation with graft rejection. Success in reversing graft rejection was achieved in 32 of the 34 (94\%) patients. The mean 
Table 1 Clinical characteristics of patients who received treatment with standard dose and low dose cyclosporine A (CSA) for the treatment of corneal graft rejection

\begin{tabular}{|c|c|c|c|}
\hline Patient characteristics & $\begin{array}{l}\text { Standard dose } \\
\operatorname{CSA}^{\mathrm{a}}(n=25)\end{array}$ & $\begin{array}{l}\text { Low dose CSA } A^{\text {a }} \\
\quad(n=9)\end{array}$ & $\begin{array}{c}\text { Total } \\
(n=34)\end{array}$ \\
\hline \multicolumn{4}{|l|}{ Age (years) } \\
\hline Mean \pm SD & $57.3 \pm 18.2$ & $67.6 \pm 14.6$ & $60.0 \pm 17.7$ \\
\hline Range & 9 to 81 & 40 to 83 & 9 to 83 \\
\hline \multicolumn{4}{|l|}{ Sex $(\%)$} \\
\hline Male & $17(68 \%)$ & $4(44 \%)$ & $21(62 \%)$ \\
\hline Female & $8(32 \%)$ & $5(56 \%)$ & $13(38 \%)$ \\
\hline \multicolumn{4}{|c|}{$\begin{array}{l}\text { Indication for keratoplasty } \\
(\%)\end{array}$} \\
\hline Corneal scar & $7(28)$ & $4(44)$ & $11(32)$ \\
\hline Corneal ulcer & $7(28)$ & $2(22)$ & $9(27)$ \\
\hline Failed graft & $6(24)$ & $1(11)$ & $7(21)$ \\
\hline Keratoconus & $2(8)$ & 0 & $2(6)$ \\
\hline Post-surgical & $1(4)$ & $1(11)$ & $2(6)$ \\
\hline Descemetocele & $2(8)$ & 0 & $2(6)$ \\
\hline Dystrophy & 0 & $1(11)$ & $1(3)$ \\
\hline \multicolumn{4}{|c|}{$\begin{array}{l}\text { Interval between surgery } \\
\text { and rejection (months) }\end{array}$} \\
\hline Mean \pm SD & $26.2 \pm 28$ & $24.7 \pm 15.4$ & $25.8 \pm 24.9$ \\
\hline Range & 1 to 120 & 4 to 53 & 1 to 120 \\
\hline \multicolumn{4}{|l|}{$\begin{array}{l}\text { Duration of symptoms } \\
\text { (days) }\end{array}$} \\
\hline Mean \pm SD & $6.2 \pm 5.4$ & $7.9 \pm 8.5$ & $6.6 \pm 6.3$ \\
\hline Range & 0 to 20 & 3 to 30 & 0 to 30 \\
\hline
\end{tabular}

${ }^{a}$ Dosage used in the two CSA regimens are described in the text.

duration of treatment required for reversal of the rejection was $13.6 \pm 12.1$ days (range $3-54$ days). The average follow-up period was $19.2 \pm 16.9$ months (range 1-55 months). Twenty-five patients received standard dose CSA while nine received low dose CSA. The comparison of these two groups is shown in Tables 1 and 2 .

Graft failure due to the rejection process occurred in two patients, one each in the standard and low dose CSA regimens. Among 32 eyes in which the rejection was reversed, one eye in the low dose CSA group developed three further episodes of rejection, but all episodes were successfully reversed using standard dose CSA therapy. Side effects of treatment included transient elevation of serum creatinine levels in three patients. The values returned to normal after decrease in dosage or cessation of CSA. As already reported, one patient developed a duodenal ulcer that responded to medical therapy.

\section{Discussion}

Oral CSA is an accepted treatment option in the prevention of allograft rejection after corneal grafting, particularly in high risk eyes. ${ }^{10}$ It appears to produce its beneficial effects by altering antigen presentation,

Table 2 Clinical outcomes in the two treatment groups

\begin{tabular}{lccc}
\hline Outcome characteristics & $\begin{array}{c}\text { Standard dose } \\
\operatorname{CSA}^{\text {a }}(n=25)\end{array}$ & $\begin{array}{c}\text { Low dose CSA } \\
(n=9)\end{array}$ & $\begin{array}{c}\text { Total } \\
(n=34)\end{array}$ \\
\hline $\begin{array}{l}\text { Irreversible rejection (\%) } \\
\text { Time to improvement }\end{array}$ & $1(4)$ & $1(11)$ & $2(6)$ \\
(days) & & & $13.6 \pm 12.1$ \\
$\quad$ Mean \pm SD & $14.0 \pm 13.7$ & $12.5 \pm 5.7$ & 3 to 54 \\
$\quad$ Range & 3 to 54 & 3 to 21 & $1(3)$ \\
Subsequent rejection (\%) & $1(4)$ & 0 & $19.2 \pm 16.9$ \\
Follow-up (months) & $18.6 \pm 18.7$ & $21.1 \pm 9.6$ & 1 to 55 \\
$\quad$ Mean \pm SD & 1 to 55 & 7 to 32 & \\
$\quad$ Range & &
\end{tabular}

a Dosage used in the two CSA regimens are described in the text. 
lymphokine production, and possibly has a role in inactivating cytotoxic T-lymphocytes. ${ }^{14}$ However, its exact mechanism of action in reversing established graft rejection is still not clear. A previous study indicated that the beneficial effect of oral CSA starts within hours of treatment with the drug, ${ }^{14}$ and it may thus be useful in the treatment of acute corneal graft rejection.

Hudde $e t a l^{6}$ reported the outcomes of a prospective randomised treatment trial in 36 patients with graft rejection. Patients enrolled in the study were a mixed group of those at low and high risk of graft rejection. They compared outcomes in two treatment arms-local corticosteroid therapy using $0.1 \%$ dexamethasone drops in the affected eye every hour for $24 \mathrm{~h}$ and one subconjunctival injection of $2 \mathrm{mg}$ betamethasone was used in one group, and a combination of this therapy with one intravenous pulse of $500 \mathrm{mg}$ methyl prednisolone in the other. Failure to reverse graft rejection was seen in 3/36 (8\%) patients, with no significant difference in outcome between the two treatment groups. They thus concluded that additional systemic treatment with $500 \mathrm{mg}$ methyl prednisolone is not useful and local corticosteroid therapy alone is adequate in patients without other risk factors for graft failure. ${ }^{6}$

In their study however, all three rejection episodes occurred in $19(16 \%)$ patients in the local treatment group, and none occurred in patients who received intravenous pulse methyl prednisolone (0/17), with equivalent follow-up of at least one year in both groups. As mentioned by Teichmann, ${ }^{15}$ the difference in outcomes in the two groups seems clinically significant, even though a statistical significance could not be demonstrated.

Comparing the outcome in reversing graft rejection in our study with that of Hudde et $a l,{ }^{6}$ both studies have equivalent success-94\% and $92 \%$ respectively. However, as discussed by Hudde et $a l^{6}{ }^{6}$ one of the possible reasons for their high success rate (compared to $50 \%,{ }^{16} 76 \%,{ }^{7}$ and $78.9 \%{ }^{17}$ in earlier studies using steroids to treat corneal graft rejection) is the earlier presentation of their patients after symptom-onset (4.3 \pm 4.5 days, range $0-14$ days). In our study, the mean duration of symptoms prior to presentation was longer $-6.6 \pm 6.3$ days (range $0-30$ days). Since increasing duration of rejection prior to treatment decreases the success rate in reversing the process, ${ }^{5}$ we feel that the results of our study are encouraging. The success in reversing corneal graft rejection in our study is also better than that in other published results. ${ }^{7-9,16,17}$

In the study by Hudde et al, ${ }^{6}$ six of the 36 corneal grafts failed during the follow-up period (range 12-40 months, mean of 25 months for local steroids only and
27.8 months for local and systemic steroids), in addition to three eyes in which the rejection could not be reversed. In the remaining 27 eyes, subsequent rejection episodes were noted in 6/13 (46\%) eyes receiving local steroid therapy, and 9/14 (64\%) eyes receiving a combination of local and intravenous pulse steroid treatment. The authors therefore state that the addition of intravenous pulse methyl prednisolone in the treatment of corneal allograft rejection, does not increase the protection against subsequent graft rejection, contrary to the findings of Hill et al. ${ }^{5}$ In contrast, in our study recurrent rejection episodes were seen in 1/32 (3\%) eyes. Although our mean follow-up is less than in the study by Hudde et $a l^{6}$ (19.2 \pm 16.9 months, range 1-55 months and 25-27.8 months, range 12-40 months respectively), we do not think that this is responsible for the considerable difference in subsequent graft rejection rates in the two studies. Since the group which received intravenous pulse steroid in their study had a rejection recurrence rate of $64 \%,{ }^{6}$ the difference in outcomes in our patients can probably be attributed to the oral CSA therapy.

In conclusion, the addition of oral CSA to current treatment approaches using topical and intravenous pulse steroid appears to be effective in reversing corneal graft rejection. This new approach may also be effective in protecting patients from subsequent rejection episodes. Our extended follow-up study confirms the safety and efficacy of this therapeutic approach. Prospective, controlled, randomised trials would be helpful in confirming the role of oral CSA in the treatment of acute corneal graft rejection.

\section{Acknowledgements}

Financial and proprietary interest: Nil. Financial Support: Supported in part by the Action for Vision Eye Foundation, Hong Kong.

\section{References}

1 Barker CF, Billingham RE. Immunologically privileged sites. Adv Immunol 1997; 25: 1-54.

2 Williams KA, Muehlberg SM, Lewis RF. The Australian Corneal Graft Registry 1996 Report. Mercury Press: Adelaide, 1997, p 11.

3 Williams KA, Muehlberg SM, Lewis RF. The Australian Corneal Graft Registry 1996 Report. Mercury Press: Adelaide, 1997, pp 47-50.

4 Vail A, Gore SM, Bradley BA, Easty DL, Rogers CA. Corneal graft survival and visual outcome: a multicentre study. Ophthalmology 1994; 101: 120-127.

5 Hill JC, Maske R, Watson P. Corticosteroids in corneal graft rejection. Oral versus single pulse therapy. Ophthalmology 1991; 98: 329-333.

6 Hudde T, Minassian DC, Larkins DFP. Randomised 
controlled trial of corticosteroid regimens in endothelial corneal allograft rejection. Br J Ophthalmol 1999; 83: 13481352.

7 Alldredge OC, Krachmer JH. Clinical types of corneal transplant rejection. Their manifestations, frequency, preoperative correlates, and treatment. Arch Ophthalmol 1981; 99: 599-604.

8 Hill JC, Maske R, Watson PG. The use of a single pulse of intravenous methyl prednisolone in the treatment of corneal graft rejection. A preliminary report. Eye 1991; 5: 420-424.

9 The Collaborative Corneal Transplantation Studies (CCTS). Effectiveness of histocompatibility matching in high-risk corneal transplantation. The Collaborative Corneal Transplantation Studies Research Group. Arch Ophthalmol 1992; 110: 1392-1403.

10 Hill JC. The use of cyclosporine in high-risk keratoplasty. Am J Ophthalmol 1989; 107: 506-510.

11 Margreiter R, Huber C, Spielberger M, Konig P. Cyclosporine in the treatment of acute cadaveric kidney graft rejection refractory to high-dose methyl prednisolone. Transplantation 1983; 36: 203-204.
12 Lam DS, Wong AK, Tham CC, Leung AT. The use of combined intravenous pulse methyl prednisolone and oral cyclosporine A in the treatment of corneal graft rejection: a preliminary study. Eye 1998; 12: 615-618.

13 Wong AK, Tham CC, Leung AT, Lam DS. The use of combined intravenous pulse methyl prednisolone and low-dose oral cyclosporin A in the treatment of corneal graft rejection: addendum to previous report. Eye 1999; 13: $584-585$

14 Hess AD, Esa AH, Colombani PM. Mechanism of action of cyclosporin: effect on cells of the immune system and on subcellular events in $\mathrm{T}$ cell activation. Transplant Proc 1988; 20: 29-40.

15 Teichmann KD. Randomised controlled trial of corticosteroid regimen in endothelial corneal allograft rejection. Br J Ophthalmol 2000; 84: 1083.

16 Gibbs DC, Batchelor JR, Werb A. The influence of tissuetype compatibility on the fate of full-thickness corneal grafts. Trans Ophthalmol Soc UK 1974; 94: 101-126.

17 Hill JC, Ivey A. Corticosteroids in corneal graft rejection: double versus single pulse therapy. Cornea 1994; 13: 383388 . 